\title{
Herbicidal Actions of Root-Applied Glufosinate Ammonium on Tomato Plants
}

\author{
Wenqi You and Allen V. Barker ${ }^{1}$ \\ Department of Plant and Soil Sciences, University of Massachusetts, Amherst, MA 01003
}

\begin{abstract}
AdDitional INDEX wORDs. Lycopersicon esculentum, ammonium toxicity, ethylene, glutamine synthetase, monoammonium2-amino-4-hydroxy(methyl)phosphinyl butanoate, phosphinothricin

Abstract. The herbicidal action of foliar applications of glufosinate-ammonium (GLA) is due to toxic accumulation of unassimilated $\mathrm{NH}_{4}{ }^{+}$in leaves; however, the effects of root-applied GLA on $\mathrm{NH}_{4}{ }^{+}$accumulation and plant growth are unknown. In a dose-response hydroponics experiment, tomato (Lycopersicon esculentum Mill.) plants were grown in nitrate-based solutions with GLA added at $0,6,12,25$, or $50 \mathrm{mg} \cdot \mathrm{L}^{-1}$. To observe plant responses to an exogenous $\mathrm{NH}_{4}{ }^{+}$ source with herbicide-induced responses, plants were grown in an $\mathrm{NH}_{4}{ }^{+}$-based solution without GLA addition. At 6 days after treatment (DAT), GLA in solution at $25 \mathrm{mg} \cdot \mathrm{L}^{-1}$ produced partial leaf wilting, chlorosis, and necrosis of foliage, and at $50 \mathrm{mg} \cdot \mathrm{L}^{-1}$, plants were fully wilted and necrotic. Ammonium $\left(\mathrm{NH}_{4}{ }^{+}-\mathrm{N}\right)$ concentration in shoots at 6 DAT increased from 0 to $6 \mathrm{mg} \cdot \mathrm{g}^{-1}$ fresh weight with increasing GLA in the nutrient solution. Ethylene evolution doubled (from 4 to $8 \mathrm{~nL} \cdot \mathrm{g}^{-1} \cdot \mathrm{h}^{-1}$, fresh weight) with increases in GLA from 0 to $25 \mathrm{mg} \cdot \mathrm{L}^{-1}$ but declined with apparent plant death with GLA at $50 \mathrm{mg} \cdot \mathrm{L}^{-1}$. Other treatments, including $\mathrm{NH}_{4}{ }^{+}$nutrition, did not induce toxicity symptoms in leaves or give increases in $\mathrm{NH}_{4}{ }^{+}$accumulation or ethylene evolution during the 6 days of the experiment. In a time-course experiment, tomato plants treated with GLA at $25 \mathrm{mg} \cdot \mathrm{L}^{-1}$ were chlorotic at $4 \mathrm{DAT}$. Ethylene evolution (fresh weight basis) rose from an initial rate of $2.6 \mathrm{~nL} \cdot \mathrm{g}^{-1} \cdot \mathrm{h}^{-1}$ to $8.3 \mathrm{~nL} \cdot \mathrm{g}^{-1} \cdot \mathrm{h}^{-1}$ after 4 days. At $9 \mathrm{DAT}$, all plants receiving this treatment died. In the time-course experiment, an exogenous $\mathrm{NH}_{4}{ }^{+}$treatment caused a slight inhibition in shoot fresh weight relative to $\mathrm{NO}_{3}{ }^{-}$nutrition with no GLA but caused no visible symptoms and only slight enhancements in $\mathrm{NH}_{4}{ }^{+}$accumulation and ethylene evolution over the 9-day period. Following GLA treatment, $\mathrm{NH}_{4}{ }^{+}$accumulated in the shoots and increased sharply with time, whereas exogenous $\mathrm{NH}_{4}{ }^{+}$led to $\mathrm{NH}_{4}{ }^{+}$accumulation primarily in roots. Results suggest that GLA was absorbed by roots and translocated to shoots, where it initiated accumulation of $\mathrm{NH}_{4}{ }^{+}$and ethylene evolution as indications of herbicidal action. Chemical name used: glufosinate-ammonium, GLA.
\end{abstract}

Glufosinate-ammonium (GLA) is a postemergence herbicide that produces phytotoxic effects by inhibiting glutamine synthetase (GS) in chloroplasts, thereby blocking synthesis of glutamine from glutamate and thus assimilation of $\mathrm{NH}_{4}{ }^{+}$ (Manderscheid and Wild, 1986). This inhibition results in $\mathrm{NH}_{4}{ }^{+}$ accumulation and ultimately in plant death (Koecher, 1983; Krieg et al., 1990; Leemans et al., 1987; Manderscheid and Wild, 1986; Tachibana et al., 1986; Wild et al., 1987). Increases in $\mathrm{NH}_{4}{ }^{+}$ concentrations in shoots are a rapid and sensitive indicator of inhibition of GS (Mersey et al., 1990). Sources of cellular $\mathrm{NH}_{4}{ }^{+}$ accumulation include $\mathrm{NO}_{3}{ }^{-}$reduction, catabolism of organic $\mathrm{N}$ compounds, and glycine to serine conversion during photorespiration (Joy, 1988; Wild et al., 1987). Ethylene evolution is a response of plants to $\mathrm{NH}_{4}{ }^{+}$toxicity and other physiological stresses (Feng and Barker, 1992) and hence may be an indicator of GLA action.

Glufosinate-ammonium is used as a foliar spray at concentrations between 100 and $500 \mathrm{mg} \cdot \mathrm{L}^{-1}$. As a nonselective herbicide, GLA has been used in minimum tillage systems, in orchards and vineyards, and in chemical fallowing and as a preharvest desiccant (Stechel et al., 1997). Its relatively short half-life in soils, 6 to $23 \mathrm{~d}$, is assumed as an indication of GLA safety (Hoerlein, 1994). However, consideration should be given to the potential of GLA remaining active for longer than the stated half-life in coarse-textured soils. Another consideration is that accumulation in plants may be herbicidal to crops, following GLA transport in soil and absorption through roots. Therefore, the current research studied the effects of root application of GLA on tomato plant

Received for publication 22 June 2000. Accepted for publication 30 Oct. 2001. Contribution of the Massachusetts Agricultural Experiment Station, paper no. 3223.

${ }^{1}$ Corresponding author. growth, $\mathrm{NH}_{4}{ }^{+}$accumulation, and ethylene evolution. Tomato was chosen for its sensitivity and documented responses to $\mathrm{NH}_{4}{ }^{+}$ toxicity (Barker et al., 1967).

\section{Materials and Methods}

Plant material and general procedures. This study was conducted with hydroponics in a greenhouse. Tomato seeds ('Heinz 1439') were germinated in 1 peat : 1 vermiculite (v:v) medium. One week after germination, seedlings were transplanted to 1.5-L opaque plastic containers filled with half-strength, $\mathrm{NO}_{3}{ }^{-}$-based solution (Hoagland No.1, Hoagland and Arnon, 1950) to preculture for 1 week. Two experiments were conducted to assess the effects of root-applied GLA (monoammonium-2amino-4-hydroxy(methyl) phosphinyl butanoate; trade name, Finale, $11.33 \%$, w/v, a.i., Hoechst Schering AgrEvo, Somerville, N.J.). A dose experiment assessed plant responses to increasing concentrations of GLA in a given time period, and a time-course experiment assessed the effects of duration of plant exposure to a herbicidal level of GLA. Each treatment was replicated in three randomized complete blocks in a greenhouse under ambient conditions of temperature $\left(\approx 18^{\circ} \mathrm{C}\right.$ day and night $)$ and light $(\approx 800$ $\left.\mu \mathrm{mol} \cdot \mathrm{m}^{-2} \cdot \mathrm{s}^{-1}\right)$ in spring 1998 . Effects of treatments were assessed by analysis of variance, regression, and by standard deviations (Steel and Torrie, 1980).

DOSE EXPERIMENT. In full-strength, $\mathrm{NO}_{3}^{-}$-based (Hoagland No. 1) solution (self-stabilized at $\mathrm{pH} 7.0$ during plant growth), GLA was added to a final active ingredient concentration of 0,6 , 12,25 , or $50 \mathrm{mg} \cdot \mathrm{L}^{-1}$. These concentrations were chosen after a preliminary experiment determined concentrations at which effects of GLA ranged from none to plant death (total wilting and necrosis of foliage) over a 7-d period. In another treatment, tomato plants received $\mathrm{NH}_{4}{ }^{+}$at $210 \mathrm{mg} \mathrm{N} / \mathrm{L}$ from an $\mathrm{NH}_{4}{ }^{+}$-based, 
modified Hoagland solution (Maynard and Barker, 1969) with no GLA and at a self-stabilized pH 4.5. Containers were checked daily and refilled with nutrition solutions as needed without further GLA additions. At $6 \mathrm{~d}$ after treatment, $\mathrm{NH}_{4}{ }^{+}$toxicity symptoms appeared, and plants from all treatments were harvested for ethylene, $\mathrm{NH}_{4}{ }^{+}$(see below), and biomass (fresh weight of shoots and roots) determinations.

TIMe-COURSE EXPERIMENT. In this experiment, tomato plants were treated with GLA at $25 \mathrm{mg} \cdot \mathrm{L}^{-1}$, which was chosen because it was effective without causing plant death in $6 \mathrm{~d}$ in the doseresponse experiment. The treatment with externally supplied $\mathrm{NH}_{4}{ }^{+}$was included as above. Entire roots and shoots for biomass and samples for $\mathrm{NH}_{4}{ }^{+}$determinations (see below) were taken every 1 or $2 \mathrm{~d}$ from the first day of treatment until plant death from herbicide treatment.

ETHYLENE ANALYSIS (BOTH EXPERIMENTS). Terminal portions

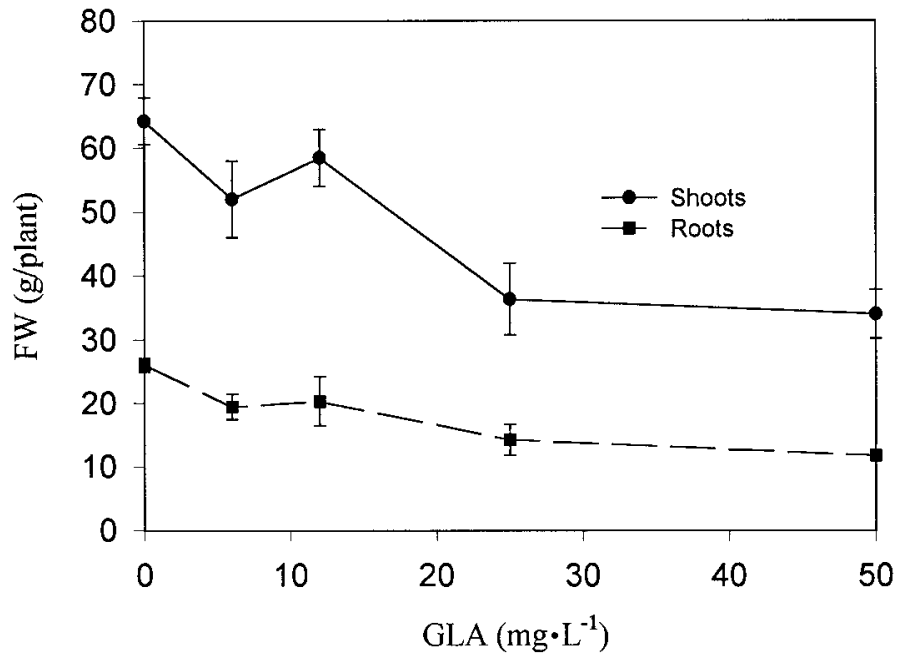

Fig. 1. Fresh weights (FWs) of tomato plants at $6 \mathrm{~d}$ after treatment as a function of concentration of GLA in solution. Each symbol represents mean $(n=3) \pm 1$ SD. Some SD bars are smaller than the data points. See text for trend analysis. Mean FWs of plants with $\mathrm{NH}_{4}{ }^{+}$without GLA are $59 \mathrm{~g} /$ plant for shoots and 19 $\mathrm{g} /$ plant for roots.

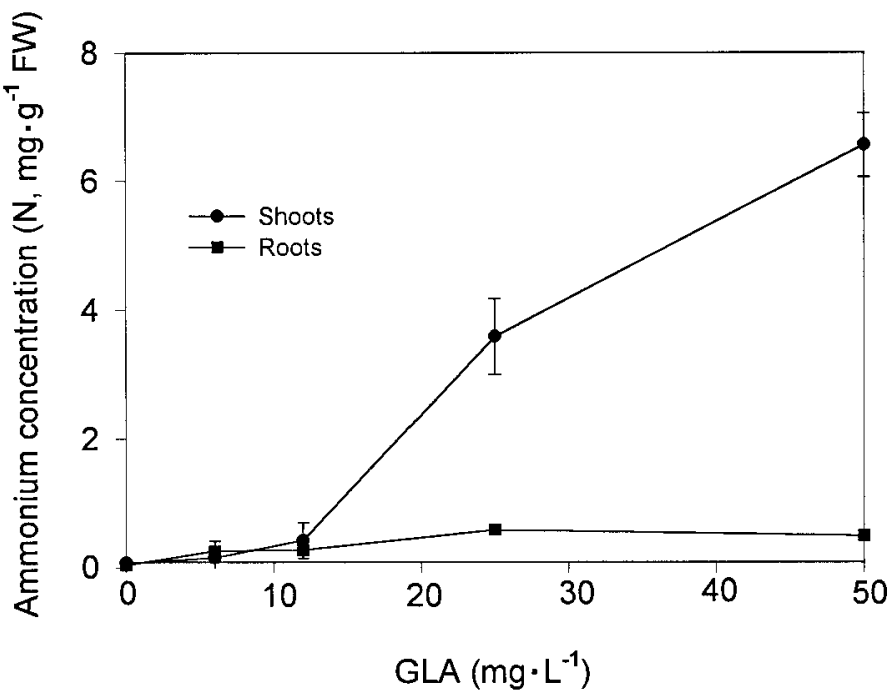

Fig. 2. Ammonium concentrations in tomato plants at $6 \mathrm{~d}$ after treatment as a function of concentration of GLA in solution. Each symbol represents mean (n = 3) $\pm 1 \mathrm{sD}$. Some SD bars are smaller than the data points. See text for trend analysis. Mean $\mathrm{NH}_{4}-\mathrm{N}$ concentrations in plants with $\mathrm{NH}_{4}{ }^{+}$without GLA are 0.35 $\mathrm{mg} \cdot \mathrm{g}^{-1}$ for shoots and $0.47 \mathrm{mg} \cdot \mathrm{g}^{-1}$ for roots. of tomato shoots including the first fully expanded leaf $(\approx 10 \mathrm{~g}$ fresh weight in each sample) were removed for determinations of ethylene evolution ( $\mathrm{rr} \mathrm{NH}_{4}{ }^{+}$, see below). The tips were placed in 500-mL canning jars, which were sealed with serum caps inserted in the lids. After 2 hours, ethylene concentration in the jars was measured by taking 2-mL portions from the jars for analysis by gas chromatography (column GDX-502, mesh 60 to 80, set at 150 ${ }^{\circ} \mathrm{C}, \mathrm{N}_{2}$ carrier gas, and flame ionization detector) (Feng and Barker, 1992).

$\mathrm{NH}_{4}{ }^{+}$ANALYSIS (BOTH EXPERIMENTS). Tissue sampling included taking tips of tomato shoots including the first fully expanded leaf on each harvest date and, separately, the entire roots. About $10 \mathrm{~g}$ of fresh tissues were homogenized with $25 \mathrm{~mL}$ of mixed solution of $1 \mathrm{M} \mathrm{KCl}$ and $0.02 \mathrm{M} \mathrm{CuSO}_{4}$ in a blender for $5 \mathrm{~min}$. After vacuum filtration of the homogenized tissue, steam distillation was employed to determine $\mathrm{NH}_{4}{ }^{+}$concentrations in the filtrate (Feng and Barker, 1992).

\section{Results}

DOSE EXPERIMENT. At $6 \mathrm{~d}$ after treatment (DAT), $\mathrm{NH}_{4}{ }^{+}$toxicity symptoms (Maynard and Barker, 1969) of leaf chlorosis, necrosis, wilting, and cupping appeared on tomato plants treated with GLA at $25 \mathrm{mg} \cdot \mathrm{L}^{-1}$. Plants treated with GLA at $50 \mathrm{mg} \cdot \mathrm{L}^{-1}$ were desiccated or totally necrotic. No visible disorders were evident on plants receiving exogenous $\mathrm{NH}_{4}{ }^{+}$or on plants receiving GLA at 6 or $12 \mathrm{mg} \cdot \mathrm{L}^{-1}$. However, tomato shoot fresh weight was inhibited (quadratic trend; $P \leq 0.05 ; \mathrm{y}=64.2-1.31 \mathrm{x}+0.014 \mathrm{x}^{2}$; $R^{2}=0.86$ ) as GLA concentration increased with $\mathrm{NO}_{3}{ }^{-}$nutrition (Fig. $1)$. Growth inhibition was $\approx 40 \%$ with GLA at 25 or $50 \mathrm{mg} \cdot \mathrm{L}^{-1}$ relative to the 0 -level of GLA. The fresh weight of tomato shoots grown on $\mathrm{NH}_{4}{ }^{+}$nutrition averaged $59 \mathrm{~g} /$ plant and was not significantly different $(P>0.05)$ from that of plants grown with $\mathrm{NO}_{3}{ }^{-}$ nutrition (63 g/plant) without GLA for $6 \mathrm{~d}$.

Herbicide in solution imparted visible changes on tomato roots, causing them to become progressively thin, sticky, and brown as GLA concentration increased above $6 \mathrm{mg} \cdot \mathrm{L}^{-1}$. Growth suppression increased (linear trend; $P \leq 0.05 ; \mathrm{y}=23.1-0.26 \mathrm{x} ; r^{2}$ $=0.83$ ) with increasing herbicide concentrations in solution (Fig. 1). High herbicide levels ( 25 or $50 \mathrm{mg}$ GLA/L) caused root stunting by $40 \%$ to $50 \%$ of fresh weight relative to plants receiving no herbicide and $\mathrm{NO}_{3}{ }^{-}$nutrition. Exogenously supplied $\mathrm{NH}_{4}{ }^{+}$did not affect $(P>0.05)$ tomato root fresh weight $(19 \mathrm{~g} /$ plant) relative to that of plants with $\mathrm{NO}_{3}{ }^{-}$nutrition without GLA (26 g/plant).

All GLA treatments led to only minor accumulation of $\mathrm{NH}_{4}{ }^{+}$ in roots, with no differences $(P>0.05)$ occurring among treatments for which the average $\mathrm{NH}_{4}{ }^{+}$concentration was $\approx 0.3 \mathrm{mg} \mathrm{N} /$ $\mathrm{g}$ fresh weight (Fig. 2). However, shoot $\mathrm{NH}_{4}^{+}$levels increased (cubic trend; $P \leq 0.05 ; \mathrm{y}=0.38-0.115 \mathrm{x}+0.015 \mathrm{x}^{2}-0.0002 \mathrm{x}^{3} ; R^{2}$ $=0.99$ ) as herbicide level increased, rising from 0.07 to over 6.5 $\mathrm{mg} \mathrm{N} / \mathrm{g}$ fresh weight (Fig. 2), with a simultaneous increase of the severity of visible symptoms (chlorosis, necrosis, and wilting). Ammonium as a sole $\mathrm{N}$ source led to $\mathrm{NH}_{4}{ }^{+}$accumulation in shoots at $0.35 \mathrm{mg} \mathrm{N} / \mathrm{g}$ and in roots at $0.47 \mathrm{mg} \mathrm{N} / \mathrm{g}$. The $\mathrm{NH}_{4}{ }^{+}$concentration from the external supply was significantly $(P \leq 0.05)$ higher in roots than in shoots, whereas $\mathrm{NH}_{4}{ }^{+}$accumulation induced by GLA was significantly $(P \leq 0.05)$ higher in shoots than in roots (Fig. 2).

Ethylene evolution rose with increases in GLA concentration to $25 \mathrm{mg} \cdot \mathrm{L}^{-1}$ (Fig. 3). The GLA treatment at $25 \mathrm{mg} \cdot \mathrm{L}^{-1}$ caused the highest ethylene evolution at 6 DAT. The GLA treatment at 50 


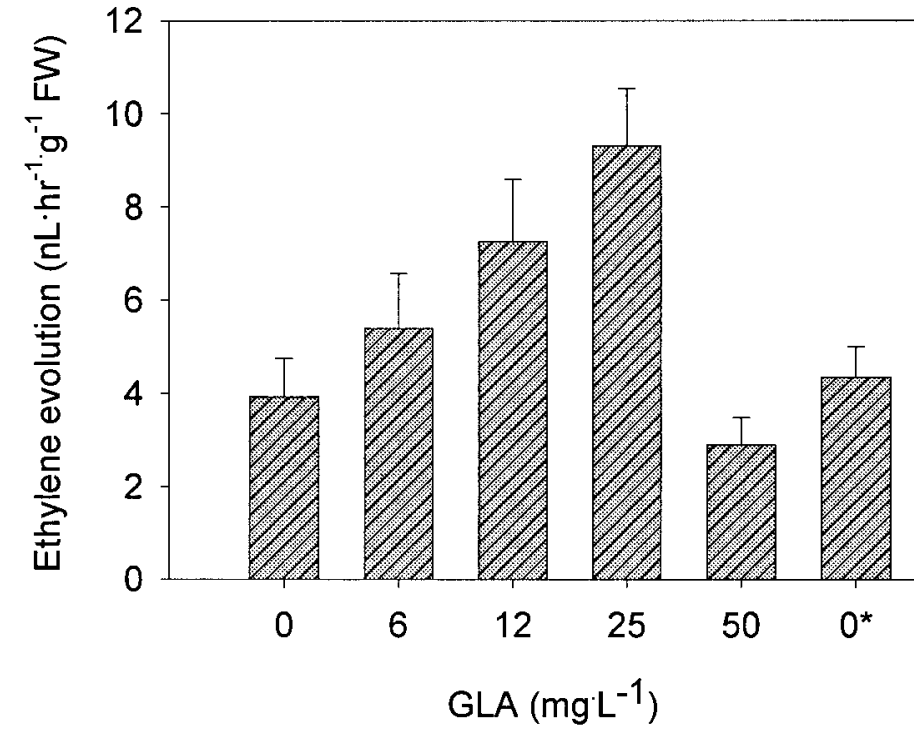

Fig. 3. Ethylene evolution of tomato plants at $6 \mathrm{~d}$ after treatment with various concentrations of concentration of GLA in solution or with $\mathrm{NH}_{4}{ }^{+}$without GLA. The $0 *$ designates treatment of $\mathrm{NH}_{4}{ }^{+}$without GLA. Vertical lines above bars represent $1 \mathrm{SD}(\mathrm{n}=3)$.
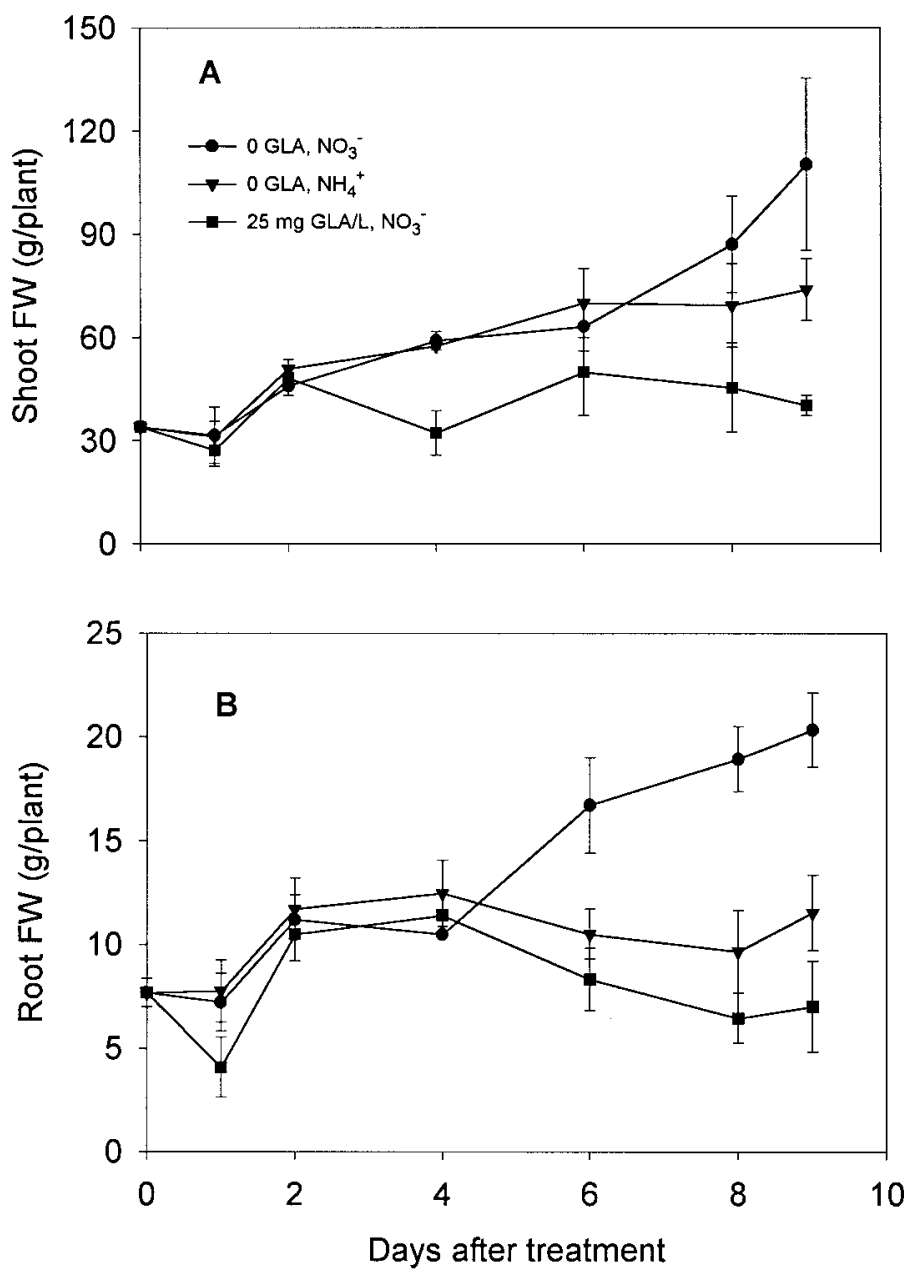

Fig. 4. Time course of tomato (A) shoot and (B) root fresh weights of plants after GLA treatment at $25 \mathrm{mg} \cdot \mathrm{L}^{-1}$ with $\mathrm{NO}_{3}{ }^{-}$nutrition or with no GLA application with $\mathrm{NO}_{3}{ }^{-}$or $\mathrm{NH}_{4}{ }^{+}$nutrition. In each section, each symbol represents mean (n $=3) \pm 1$ SD. Some SD bars are smaller than the data points. See text for trend analysis. $\mathrm{mg} \cdot \mathrm{L}^{-1}$ desiccated the foliage and depressed ethylene evolution relative to that of the other treatments at $6 \mathrm{DAT}$. Exogenous $\mathrm{NH}_{4}^{+}$ did not cause an increase in ethylene evolution during this time period relative to the treatment with $\mathrm{NO}_{3}{ }^{-}$and no GLA.

Time-COURSE OF HERBICIDE EFFECT. Tomato plants treated with GLA at $25 \mathrm{mg} \cdot \mathrm{L}^{-1}$ developed toxicity symptoms of leaf yellowing and wilting at 6 DAT and were fully necrotic at 9 DAT. Inhibition of tomato shoot growth (Fig. 4A) by GLA occurred at 4 DAT, and inhibition of root growth (Fig. 4B) occurred at 6 DAT. The exogenous $\mathrm{NH}_{4}{ }^{+}$supply did not damage plant appearance at any time and did not suppress growth in the early course of the experiment. However, at the end of the experiment (9 DAT), shoot fresh weight with $\mathrm{NH}_{4}{ }^{+}$nutrition (74 g/plant) was lower than with $\mathrm{NO}_{3}{ }^{-}$nutrition without herbicide $(110 \mathrm{~g} / \mathrm{plant})$ (Fig. 4A). A suppression in root growth by $\mathrm{NH}_{4}{ }^{+}$nutrition, relative to $\mathrm{NO}_{3}{ }^{-}$nutrition, was evident at and following 6 DAT (Fig. 4B).

Either GLA application or exogenous $\mathrm{NH}_{4}{ }^{+}$led to $\mathrm{NH}_{4}{ }^{+}$ accumulation in plant shoots or roots with time (Fig. 5A). However, the accumulation patterns were different. Nutritional $\mathrm{NH}_{4}{ }^{+}$ caused much smaller increases of $\mathrm{NH}_{4}{ }^{+}$accumulation in shoots and roots with time than the GLA treatment. In contrast with the effects from $\mathrm{NH}_{4}{ }^{+}$nutrition, $\mathrm{NH}_{4}{ }^{+}$accumulation induced by GLA was partitioned to shoots and increased with time (Fig. 5A). At 9 DAT, more than $90 \%$ of accumulated $\mathrm{NH}_{4}{ }^{+}$in response to GLA was in shoots based on concentrations detected. In shoots, $\mathrm{NH}_{4}{ }^{+}$ accumulation caused by GLA was curvilinear (quadratic trend; $P$ $\leq 0.05 ; \mathrm{y}=-0.52+2.30 \mathrm{x}-0.09 \mathrm{x}^{2} ; R^{2}=0.99$ ) and was up to six times that caused by exogenous $\mathrm{NH}_{4}^{+}$, which showed no change $(P>0.05)$ with time (Fig. 5A). In roots, however, exogenously supplied $\mathrm{NH}_{4}{ }^{+}$led to 2 to 3 times higher $\mathrm{NH}_{4}{ }^{+}$accumulation than GLA treatments, although the concentrations were much smaller than those occurring in shoots with GLA treatment (Fig. 5B). The increases in roots were curvilinear with time (with $\mathrm{NH}_{4}{ }^{+}, \mathrm{y}=0.03$ $+0.21 \mathrm{x}-0.018 \mathrm{x}^{2}, R^{2}=0.96$; and with GLA, $\mathrm{y}=0.03+0.057 \mathrm{x}$ $\left.-0.005 \mathrm{x}^{2}, R^{2}=0.67\right)$. Nitrate nutrition without GLA had no effect on $\mathrm{NH}_{4}{ }^{+}$accumulation with time.

At 4 DAT, ethylene production by GLA-treated plants exhibited a sharp rise to $8.3 \mathrm{~nL} \cdot \mathrm{g}^{-1} \cdot \mathrm{h}^{-1}$ from the initial rate of 2.6 units (Fig. 6). In a curvilinear trend (cubic regression; $P \leq 0.05 ; \mathrm{y}=2.80$ $\left.-0.27 \mathrm{x}+0.62 \mathrm{x}^{2}-0.66 \mathrm{x}^{3} ; R^{2}=0.89\right)$, this increase occurred concurrently with the visual appearance of $\mathrm{NH}_{4}{ }^{+}$toxicity symptoms. When GLA-treated plants died at 9 DAT, their ethylene evolution decreased to the level of plants not treated with herbicide. During the 9-d experimental period, ethylene evolution by tomato plants receiving no herbicide remained low, regardless of the $\mathrm{N}$ source, and showed no significant trends with time (Fig. 6).

\section{Discussion}

This study demonstrated herbicidal action of root-applied GLA. The increase in shoot $\mathrm{NH}_{4}{ }^{+}$level following root application of GLA was evidence of herbicidal action, since $\mathrm{NH}_{4}{ }^{+}$accumulation is an indicator of glutamine synthetase inhibition (Manderscheid and Wild, 1986; Mersey et al., 1990). In this study, GLA at 25 or $50 \mathrm{mg} \cdot \mathrm{L}^{-1}$ in solution caused substantial $\mathrm{NH}_{4}^{+}$ accumulation (much greater than $1 \mathrm{mg} \mathrm{NH}_{4}{ }^{+}-\mathrm{N} / \mathrm{g}$ fresh weight) in shoot tissue, plant growth suppression, and, within 6 to $9 \mathrm{~d}$, plant death. The increase in shoot $\mathrm{NH}_{4}{ }^{+}$appeared before the onset of symptoms and death. Mersey et al. (1990) and other researchers (Diaz et al., 1995; Lacuesta et al., 1989; Seelye et al., 1995) observed a similar sequence of plant responses with GLA applied 

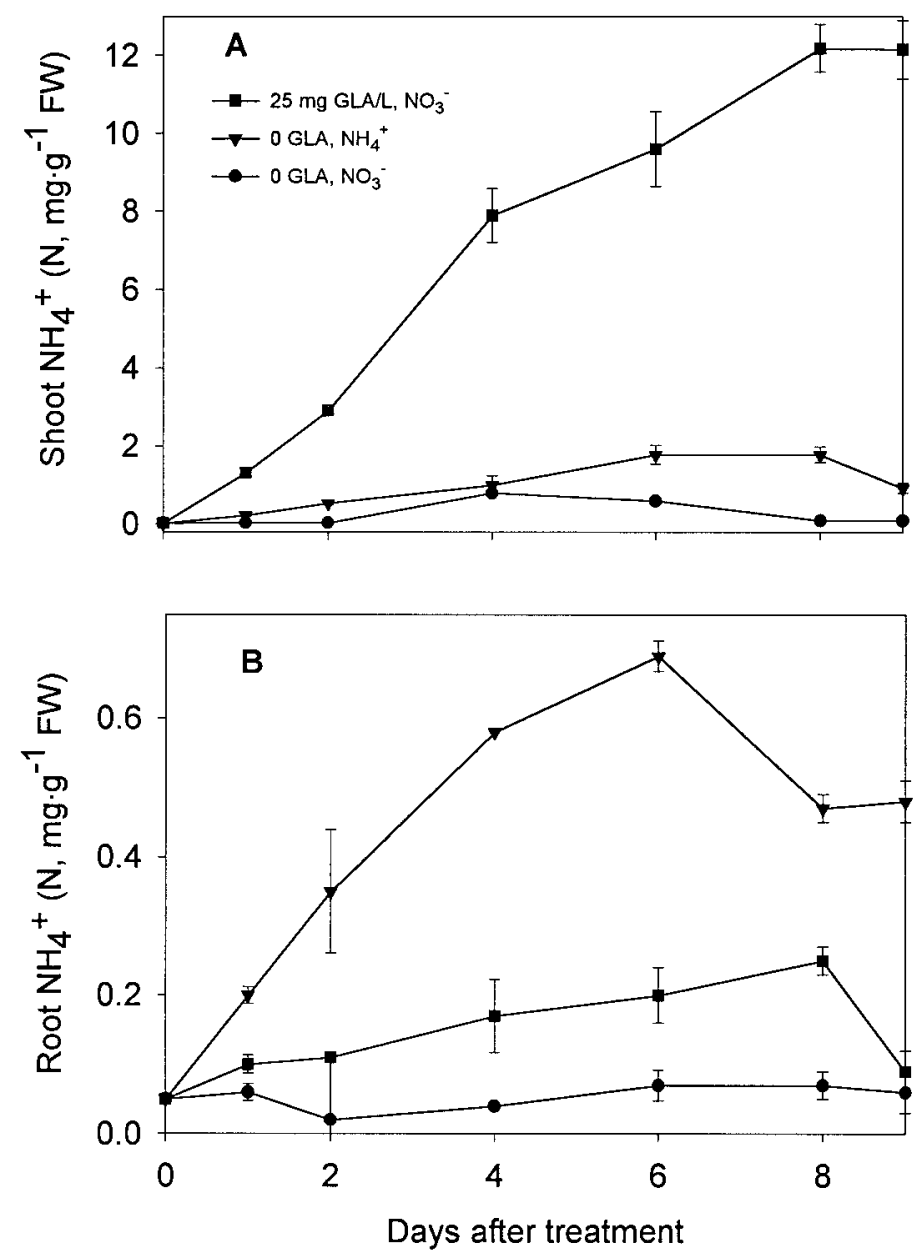

Fig. 5. Time course of $\mathrm{NH}_{4}^{+}$accumulation in tomato (A) shoots and (B) roots after treatment with GLA at $25 \mathrm{mg} \cdot \mathrm{L}^{-1}$ with $\mathrm{NO}_{3}{ }^{-}$nutrition or with no GLA application with $\mathrm{NO}_{3}{ }^{-}$or $\mathrm{NH}_{4}{ }^{+}$nutrition. In each section, each symbol represents mean $(\mathrm{n}=3) \pm 1$ SD. Some SD bars are smaller than the data points. See text for trend analysis.

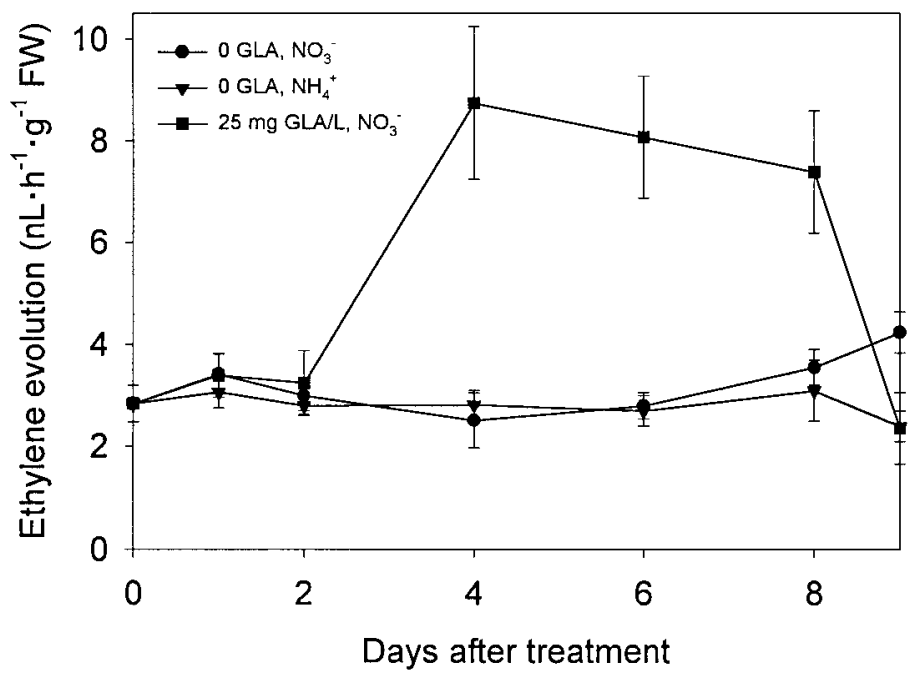

Fig. 6. Time course of ethylene evolution of tomato plants after treatment with GLA at $25 \mathrm{mg} \cdot \mathrm{L}^{-1}$ with nitrate nutrition or with no GLA application with $\mathrm{NO}_{3}{ }^{-}$ or $\mathrm{NH}_{4}{ }^{+}$nutrition. Each symbol represents mean $(\mathrm{n}=3) \pm 1$ SD. Some SD bars are smaller than the data points. See text for trend analysis. as a foliar spray. In the current study, $\mathrm{NH}_{4}{ }^{+}$concentrations in roots were low and did not relate to appearance of foliar symptoms, even though GLA was applied to the roots. Shoot accumulation exceeding $1 \mathrm{mg} \mathrm{NH}_{4}{ }^{+}-\mathrm{N} / \mathrm{g}$ fresh weight following GLA application was sufficient to impart $\mathrm{NH}_{4}^{+}$phytotoxicity (Maynard and Barker, 1969).

Patterns of $\mathrm{NH}_{4}^{+}$accumulation, ethylene evolution, and symptoms of phytotoxicity suggest root absorption and translocation of GLA from roots to shoots. The fact that sharp increases of $\mathrm{NH}_{4}{ }^{+}$ occurred in plant shoots and not in roots was taken as evidence of absorption and translocation of GLA. The action site of GLA is the chloroplasts of leaves (Ridely and McNally, 1985), the principal site of reduction of $\mathrm{NO}_{2}{ }^{-}$to $\mathrm{NH}_{4}{ }^{+}$in plants and the major site of assimilation of metabolically generated $\mathrm{NH}_{4}{ }^{+}$. In the time period of this experiment, no evidence was obtained for production and translocation of $\mathrm{NH}_{4}{ }^{+}$from roots to shoots and subsequent phytotoxicity of $\mathrm{NH}_{4}{ }^{+}$. In fact, $\operatorname{root} \mathrm{NH}_{4}{ }^{+}$concentration with $\mathrm{NH}_{4}{ }^{+}$in the nutrient solution was higher than that in the shoots, suggesting that the roots were retaining $\mathrm{NH}_{4}{ }^{+}$. Following GLA application in solution, leaf $\mathrm{NH}_{4}{ }^{+}$concentrations were 10 to 20 times those in roots depending on the period of exposure to GLA. Furthermore, the relationships among ethylene evolution by shoots, visible symptoms, and the distinct pattern of $\mathrm{NH}_{4}{ }^{+}$accumulation following GLA application to roots also suggested translocation of GLA from roots to shoots and herbicidal action in the shoots.

Ethylene evolution was enhanced following root application of GLA. At $1 \mathrm{~d}$ before the appearance of toxicity symptoms, ethylene evolution increased to double or triple the initial rate. Hall et al. (1985) with 2,4-D (2,4-dichlorophenoxyacetic acid) and Harber and Fuchigami (1989) with clopyralid (3,6-dichloro2-pyridinecarboxylic acid) and picloram (4-amino-3,5,6-trichloro2-pyridinecarboxylic acid) also demonstrated ethylene evolution by herbicide-treated plants. Ethylene acts as a general signal of various environmental and biological stresses in plants (Abeles et al., 1992) and occurs specifically with plants under stress of $\mathrm{NH}_{4}{ }^{+}$ toxicity (Feng and Barker, 1992).

Although the sensitivity to GLA varies with plant species, growth status, and soil and environmental conditions, the effective rate for foliar application is several hundred milligrams of active ingredient per liter (Carlson and Burnside, 1984). That amount is several-fold the maximum root applications shown to be effective herein. This comparison in concentrations does not mean that root applications of GLA are more effective than foliar applications, since the duration of exposure of plants to GLA in nutrient solutions likely exceeds that from a single application of foliar spray. It is clear, however, that root-applied GLA is physiologically active and capable of imparting plant responses similar to those of foliarly applied GLA. These results suggest that GLA present in a soil solution at $25 \mathrm{mg} \cdot \mathrm{L}^{-1}$ or higher may result in severe phytotoxicity to tomato. Effects of sublethal concentrations of GLA on field-grown crops require further investigations.

\section{Literature Cited}

Abeles, F.B., P.W. Morgan, and M.E. Saltveit. 1992. Ethylene in plant biology. Academic Press, San Diego.

Barker, A.V., D.N. Maynard, and W.H. Lachman. 1967. Induction of tomato stem and leaf lesions, and potassium deficiency, by excessive ammonium nutrition. Soil Sci. 103:319-327.

Carlson, K.L. and O.C. Burnside. 1984. Comparative phytotoxicity of glyphosate, SC-0545, and HOE-0061. Weed Sci. 32:841-844. 
Diaz, A., H. Maza, B. Gonzalez-Moro, M. Lacuesta, C. GonzalezMurua, and A. Munoz-Rueda. 1995. Phosphinthricin reverts the ammonia-dependent enhancement of phosphoenolpyryruvate carboxylase activity. J. Plant Physiol. 145:11-16.

Feng, J. and A.V. Barker. 1992. Ethylene evolution and ammonium accumulation by nutrient-stressed tomatoes grown with inhibitors of ethylene synthesis or action. J. Plant Nutr. 15:155-167.

Hall, J.C., P.K. Bassi, M.S. Spencer, and W.H. Van den Born. 1985. An evaluation of the role of ethylene in herbicidal injury induced by picolram or clopyralid in rape seed and sunflower plants. Plant Physiol. 79:18-23.

Harber, R.M. and L.H.W. Fuchigami. 1989. Ethylene-induced stress resistance, p. 81-90 In: P.H. Li (ed.). Low temperature stress physiology in crops. CRC Press, Inc., Boca Raton, Fla.

Hoagland, D.R. and D.I. Arnon. 1950. The water-culture method for growing plants without soil. Calif. Agr. Expt. Sta. Circ. 347.

Hoerlein, G. 1994. Glufosinate (phosphinothricin), a natural amino acid with unexpected herbicidal properties. Rev. Environ. Contam. Toxicol. 138:73-145.

Joy K.W. 1988. Ammonia, glutamine, and asparagine: A carbonnitrogen interface. Can. J. Bot. 66:2103-2109.

Koecher H. 1983. Influence of the light factor on physiological effects of the herbicide phosphinothricin ammonium. Aspects Appl. Biol. 4:227234.

Krieg, L.C., M.A. Walker, T. Senatna, and B.D. McKersie. 1990. Growth, $\mathrm{NH}_{4}^{+}$accumulation and glutamine synthetase activity in alfalfa (Medicago sativa L.) shoots and cell cultures treated with phosphinothricin. Plant Cell Rpt. 9:80-83.

Lacuesta, M., B. Gonzalez-Moro, C. Gonzalez-Murua, P. AparicioTejo, and A. Munoz-Rueda. 1989. Effect of phosphinothricin (glufosinate) on activities of glutamine synthetase and glutamate dehydrogenase in Medicago sativa L. J. Plant Physiol. 134:304-307.
Leemans J., M. De Block, K. D’Halluin, J. Boterman, and W. De Greef. 1987. The use of glufosinate as a selective herbicide on genetically engineered resistant tobacco plants. Proc. Brit. Crop Protection Conf. Weeds 3:867-870.

Manderscheid R. and A. Wild. 1986. Studies on the mechanism of inhibition by phosphinothricin of glutamine synthestase isolated from Triticium aestivum. J. Plant Physiol. 123:135-142.

Maynard, D.N. and A.V. Barker. 1969. Studies on the tolerance of plants to ammonium nutrition. J. Amer. Soc. Hort. Sci. 94:235-239.

Mersey B.G., J.C. Hall, D.M. Anderson, and C.J. Swanton. 1990. Factors affecting the herbicidal activity of glufonsinate-ammonium absorption, translocation and metabolism in barley and green foxtail. Pesticide Biochem. Physiol. 37:90-98.

Ridely, S.M. and S.F. McNally. 1985. Effects of phosphinothicin on the isoenzymes of glutamine synthetase isolated from plant species which exhibit varying degrees of susceptibility to the herbicide. Plant Sci. 39:31-36.

Seelye, J.F., W.M. Borst, G.A. King, P.J. Hannan, and D. Maddocks. 1995. Glutamine synthetase activity, $\mathrm{NH}_{4}^{+}$accumulation and growth of callus cultures of Asparagus officinalis L. exposed to high $\mathrm{NH}_{4}^{+}$or phosphinothricin. 1995. J. Plant Physiol. 146:686-692.

Steckel, G.J., S.E. Hart, and L.M. Wax. 1997. Absorption and translocation of glufosinate in four weed species. Weed Sci. 45:378-381.

Steel, R.G.D. and J.H. Torrie. 1980. Principles and procedures of statistics. $2^{\text {nd }}$ ed. McGraw Hill, New York.

Tachibana K., T. Watenaba, Y. Sekizawa, and T. Takematse. 1986. Accumulation of ammonia in plants treated with bialaphos. J. Pesticide Sci. 11:33-37.

Wild A., H. Sauer, and W. Ruhle. 1987. The effects of phosphinothricin (glufosinate) on photosynthesis. I. Inhibition of photosynthesis and ammonia accumulation. Zeitschrift fur Naturforschung-Section CBiosciences 42c:263-269. 